\title{
Individual variation of tentorial notch morphometry in a series of neurocritical patients
}

\author{
Variación individual de la morfometría de la hendidura tentorial en una serie de pacientes \\ neurocríticos
}

Pedro GRILLE'1,2, Alberto BIESTRO'1, Osmar TELIS ${ }^{3}$, Federico VERGA2 Nicolas SGARB/3

\begin{abstract}
Background: Cadaveric studies on humans have shown anatomical variabilities in the morphometric characteristics of the tentorial notch. These anatomical variations could influence the worsening of neurocritical patients. Objectives: 1) To investigate the morphometric characteristics of the tentorial notch in neurocritical patients using computed tomography (CT); 2) To investigate the correlation between tentorial notch measurements by CT and by magnetic resonance imaging (MRI); and 3) To analyze the individual variability of the tentorial notch anatomy seen in neurocritical patients. Methods: Prospective series of neurocritical patients was examined. An imaging protocol for measurements was designed for CT and MRI. The level of the agreement of the measurements from CT and MR images was established. According to the measurements found, patients were divided into different types of tentorial notch. Results: We studied 34 neurocritical patients by CT and MRI. Measurements of the tentorial notch via CT and MRI showed significant agreement: concordance correlation coefficient of 0.96 for notch length and 0.85 for maximum width of tentorial notch. Classification of tentorial notch measurements according to the criteria established by Adler and Milhorat, we found the following: 15 patients (58\%) corresponded to a "short" subtype; 7 (21\%) to "small”; 3 (9\%) to "narrow"; 2 (6\%) to "wide"; 2 (6\%) to "large"; 1 (3\%) to "long"; and 4 (12\%) to "typical". Conclusions: The anatomical variability of the tentorial notch could be detected in vivo by means of CT scan and MRI. Good agreement between the measurements made using these two imaging methods was found.
\end{abstract}

Keywords: Dura Mater; Anatomic Variation; Cognitive Dysfunction; Encephalocele; Tentorium Cerebelli; Cerebral Herniation.

\section{RESUMEN}

Antecedentes: Estudios cadavéricos en humanos han mostrado variabilidad anatómica en las características morfométricas de la hendidura tentorial (HT). Estas variaciones anatómicas podrían influir en el neurodeterioro agudo de los pacientes neurocríticos. Objetivos: 1) Investigar las características morfométricas de la HTen pacientes neurocríticos mediante tomografía computarizada (TC); 2) Investigar la correlación de las mediciones de la HT realizadas por TC y resonancia magnética (RM); 3) Analizar la variabilidad individual de la anatomía de la HT observada en pacientes neurocríticos. Métodos: Se examinó una serie prospectiva de pacientes neurocríticos. Se diseñó un protocolo de imágenes para mediciones por TC y RM. Se estableció la concordancia de las mediciones realizadas mediante TC y RM. Según las mediciones encontradas, los pacientes se dividieron en diferentes tipos de HT. Resultados: Estudiamos 34 pacientes neurocríticos por TC y RM. Las mediciones de la HT por TC y RM mostraron una concordancia significativa: coeficiente de correlación de concordancia de 0,96 para la longitud de la HT y 0,85 para el ancho máximo de la HT. Clasificando las medidas de la HT de acuerdo con los criterios establecidos por Adler y Milhorat, encontramos: 15 pacientes (58\%) correspondieron al subtipo "corto", 7 (21\%) al "pequeño", 3 (9\%) al "estrecho", 2 (6\%) a "ancho", 2 (6\%) al "grande", 1 (3\%) al "largo" y 4 (12\%) al "típico". Conclusiones: Se pudo detectar variabilidad anatómica de la HT in vivo, mediante TC y RM. Se encontró una buena concordancia en las medidas obtenidas con ambos métodos imagenológicos.

Palabras clave: Duramadre; Variación Anatómica; Disfunción Cognitiva; Encefalocele; Tienda del Cerebelo; Hernia Cerebral.

\footnotetext{
${ }^{1}$ Universidad de la República, Facultad de Medicina, Hospital de Clínicas, Unidad de Cuidados Intensivos, Montevideo, Uruguay. ${ }^{2}$ Administración de los Servicios de Salud del Estado, Hospital Maciel, Unidad de Cuidados Intensivos, Montevideo, Uruguay.

${ }^{3}$ Universidad de la República, Facultad de Medicina, Departamento de Radiología, Montevideo, Uruguay.

PG (D) https://orcid.org/0000-0002-2099-4378;AB (D) https://orcid.org/0000-0001-5147-0027; OT (DD https://orcid.org/0000-0002-7150-763X;

FV (iD) https://orcid.org/0000-0002-7917-1616; NS (iD) https://orcid.org/0000-0002-9613-4868

Correspondence: Pedro Grille; Email: grillepm@gmail.com.

Conflict of interest: There is no conflict of interest to declare.

Authors' contributions: PG: conceptualization, investigation, methodology, data curation, formal analysis, project administration, supervision, validation, writing original draft, review and editing; AB: conceptualization, methodology, supervision, validation, writing original draft, review and editing; OT: methodology, data curation, formal analysis, validation, review and editing; FV: methodology, statistical analysis, data curation, formal analysis, validation, review and editing; NS: methodology, formal analysis, validation, review and editing.
}

Received on July 20, 2020; Received in final form on October 19, 2020; Accepted on November 02, 2020. 


\section{INTRODUCTION}

Pathological processes that increase intracranial volume may generate ischemic lesions through compression and distortion of the brain and its vessels. These displacements of brain structures are consequent to intracranial pressure gradients that are usually not detected by means of standard monitoring of intracranial pressure. The maximum clinicalpathological expression of these displacements are herniation syndromes ${ }^{1,2,3,4,5}$.

The introduction of CT and, especially, MRI has promoted a review of the classic concepts of brain displacement, with emphasis on the early biophysical phenomena of brainstem distortion ${ }^{6,7,89}$. In this way, it can be established that there are basically three clinical determinants of such displacements: a) the volume of the mass lesions; b) their topography; and c) the rapidity of their growth.

On the other hand, the role that anatomical variations, especially those observed in the morphometry of the tentorial incisura, can play in this dynamic remains unclear. It has been suspected that certain anatomical variants of the tentorium could somehow influence the phenomenon of clinical deterioration in the presence of a focal mass that grows intracranially.

Until now, little attention has been given to individual anatomical variations of the tentorium and their relationship with the phenomenon of clinical deterioration and outcome. In addition to the classic studies of Corsellis and Sunderland last century, the meticulous study by Adler and Milhorat has, in more recent years, provided valuable information and has opened the doors to further clinical research on this subject ${ }^{10,11,12}$. The latter authors categorized the different anatomical variations of the tentorial notch in cadavers and correlated these variations with measurements through MRI. They divided these variations into seven types. So far, no studies have been conducted on healthy volunteers and, even less, on neurocritical patients.

The objectives of our study were the following: a) to design a CT protocol for studying the individual morphometric characteristics of the tentorial notch in neurocritical patients; b) to determine the correlation between measurements obtained through a CT protocol and those made using MRI, since MRI is considered to be the "gold standard" for intracranial morphometry in vivo; and c) to analyze the individual variability of tentorial notch anatomy in vivo, in neurocritical patients.

\section{METHODS}

A prospective study was conducted on non-consecutive patients admitted to the intensive care units (ICUs) of Clinicas and Maciel hospitals with acute and severe neurological disease and initial Glasgow Coma Scale scores (GCSs) of 8 or less (including head trauma, subarachnoid hemorrhage (SAH), intracerebral hemorrhage and cerebral infarction), between January 2015 and December 2017.

We included the patients on whom a MRI examination could be done during their stay in the ICU. CT scans were performed within the first $48 \mathrm{~h}$ after admission to the ICU whereas MRIs were done when the patient was stable enough. The MRIs were performed on average 14 days after the CT scan. Patients under 15 years of age, pregnant patients and patients presenting physiological instability that prevented transfer for performing CT and MRI scans were excluded from our study.

This study was evaluated and approved by the ethics committees of Maciel and Clinicas hospitals. An informed consent statement was presented to and signed by the relative responsible for each patient. Patients were assured of confidentiality with regard to management of their medical history data.

Therapeutic management of patients was carried out in accordance with the corresponding protocols used in each ICU. These include general directives relating to minimizing the phenomena of secondary brain injury, management of intracranial hemodynamics, prophylaxis and treatment of complications.

In order to perform measurements on the tentorial incisura in vivo, two detailed measurement protocols were applied for both CT and MRI scans. As described in the study by Adler and Milhorat, the following landmarks were used as reference points to define tentorial notch morphometry: the dorsum sellae, the interpeduncular fossa and the apex of the tentorial incisura ${ }^{12}$. Based on these reference points, the following distances were established: MNW (maximum width of the tentorial notch in the axial plane); and NL (length of the tentorial notch, determined by the distance between the posterosuperior edge of the dorsum sellae and the apex of the incisura, in the sagittal plane). Figure 1 schematizes the tentorial notch with its corresponding measurements.

\section{Imaging protocols for studying the tentorial notch}

1) MRI imaging protocol: This was established by obtaining brain image sequences in the sagittal and coronal planes, using high resolution T2-weighted imaging. In new MRI scans, we prefer to use high-resolution 3D sequences, either $\mathrm{T} 1$ or T2 weighted, and even volumetric sequences with cisternographic effect (FIESTA/CISS/CUBE sequences), which provide an excellent display of the tentorial notch anatomy. In this manner, it is possible to obtain images in the three planes with excellent resolution.

2) CT imaging protocol: In the usual cranial CT protocol, the posterior fossa study algorithm was replaced by: 1) helical acquisition, in Pitch 1, with $3 \mathrm{~mm}$ slices every $2.5 \mathrm{~mm}$, from the base of the skull to the external occipital tuberosity; 2) angulation following the supraorbital-meatal line (to decrease the 


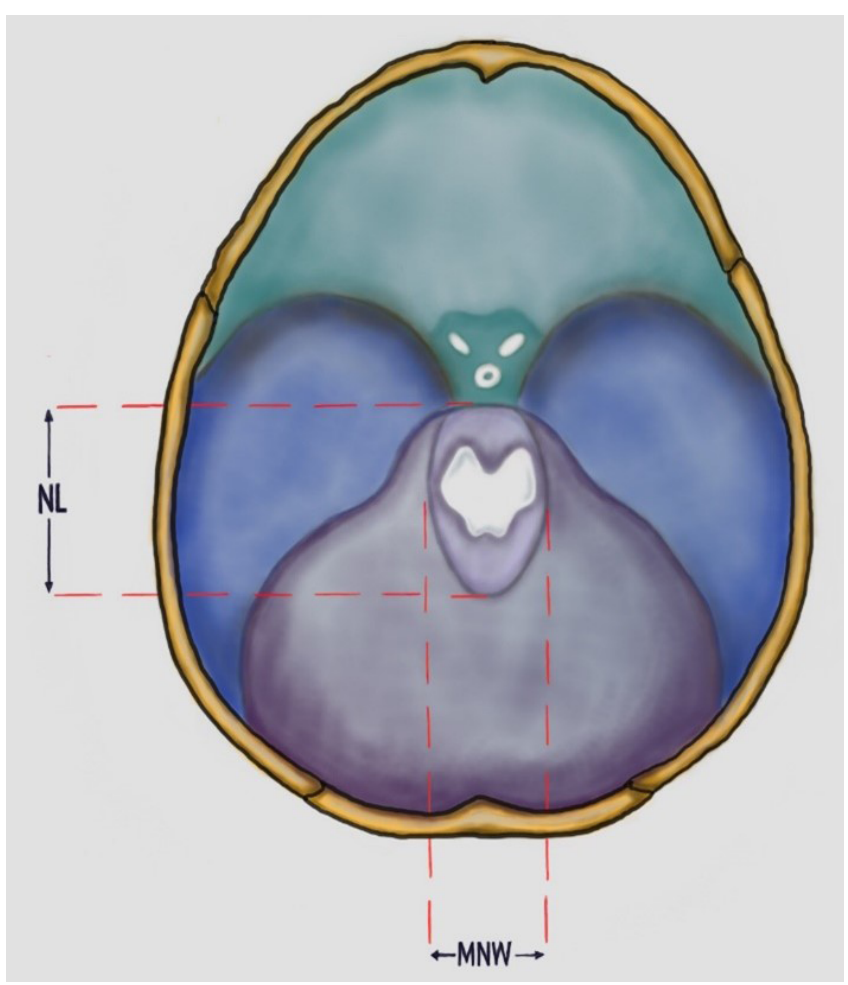

NL: notch length; MNW: maximum notch width.

Figure 1. Diagram of the tentorial notch and the measurements obtained in our study.

radiation to the lens); 3) coronal and sagittal reconstructions based on the data obtained through the acquisition described here. NL measurements were made in the mid-sagittal plane and MNW measurements in the axial plane, in coronal view, with extrapolation of the reference points described in the MRI algorithm. In a multidetector CT scan, a single acquisition run is enough to obtain images in the three planes, with excellent resolution of the tentorial notch.

The imaging measurements were made by two experienced neuroradiologists (OT and NS) who were blinded to the other modality. The images were presented in random order, which differed between the modalities, and the measurements were made at different time points.

\section{Statistical analysis}

All the demographic data were expressed as the mean \pm standard deviation (SD) for quantitative variables and as percentages for qualitative variables. The Kolmogorov-Smirnoff test was used to determine whether the variables presented normal distribution. The t test for paired samples was used to compare the means. Each pair of measurements from CT and MRI was graphically displayed in a dispersion diagram. Lin's concordance correlation coefficient (CCC) was calculated to quantify the strength of the agreement between CT and MRI measurements. Bland-Altman analysis and mountain plots were used to complement the comparison of the measurements from the two imaging methods. The statistical analyses were performed using the Statistical Package for the Social Sciences software (SPSS, version 17.0) and the MedCalc software (version 13.0).

\section{RESULTS}

Thirty-four patients were studied: 14 (41\%) had suffered traumatic brain injury; $8(24 \%)$, spontaneous intracerebral hemorrhage; 7 (21\%), subarachnoid hemorrhage; and 5 (15\%), ischemic stroke. The morphometric characteristics of the tentorial notch were assessed by means of CT and MRI. Table 1 summarizes the basic demographic data and measurements of the tentorial notch in our patients. The percentage of our patients with intracranial hypertension was $48 \%$.

The NL and MNW measurements via CT and MRI using both protocols, respectively, showed normal distribution. The mean difference between NL measured with MRI (NLMRI) and with CT (NLCT) was $-0.14 \pm 2.26 \mathrm{~mm}(\mathrm{p}=\mathrm{NS})$. The mean difference between MNW measured with MRI (MNWMRI) and with CT (MNWCT) was $0.02 \pm 1.70 \mathrm{~mm}(\mathrm{p}=\mathrm{NS})$. Figure 2 shows the correlation plots for tentorial notch measurements with both imaging methods.

The Bland-Altman and mountain plots representing the agreement or concordance between the CT and MRI measurements of the tentorial notch are shown in Figure 3. The CCC was 0.96 (95\% CI: 0.92-0.98) for NL and 0.85 (95\% CI: 0.73-0.92) for MNW.

Figure 4 shows a clinical example of a tentorial notch evaluation by means of MRI and CT on the same patient. Morphometric concordance can be seen.

Based on the criteria established by Adler and Milhorat, the tentorial notch subtypes among our neurocritical patients were categorized, taking into consideration the CT measurements. In those authors' necropsy study, they categorized the tentorial notch into seven subtypes, which are summarized in Table 2. In our population of patients, we found the following individual morphometric variations of the tentorial notch: 15 patients (58\%) corresponded to "short", 7 (21\%) to "small", 3 (9\%) to "narrow", 2(6\%) to "wide", 2 (6\%) to "large", 1 (3\%) to "long" and $4(12 \%)$ to "typical" subtypes, respectively. Table 2 shows the percentage distribution of the tentorial notch morphometry found in the present study and compares this with what was found by Adler and Milhorat in their necropsy study.

\section{DISCUSSION}

The tentorial notch or incisura is a complex tridimensional space defined by the free edges of the tentorium cerebelli. It was described initially through the studies of Kernohan and Reid $^{9,10}$ and more recently in studies by Klintworth, Osborn, 
Table 1. CT and MRI measurements of the tentorial notch (NL and MNW), with the corresponding notch categorization.

\begin{tabular}{|c|c|c|c|c|c|c|c|c|c|}
\hline Sex & Age & Diagnosis & $\begin{array}{l}\mathrm{NLCT} \\
(\mathrm{mm})\end{array}$ & $\begin{array}{l}\text { NL MRI } \\
(\mathrm{mm})\end{array}$ & $\begin{array}{c}\mathrm{NL} \\
\text { difference } \\
\mathrm{MRI}-\mathrm{CT}(\mathrm{mm})\end{array}$ & $\begin{array}{l}\text { MNW CT } \\
(\mathrm{mm})\end{array}$ & $\begin{array}{l}\text { MNW MRI } \\
(\mathrm{mm})\end{array}$ & $\begin{array}{c}\text { MNW } \\
\text { difference } \\
\text { MRI - CT (mm) }\end{array}$ & $\begin{array}{l}\text { Notch } \\
\text { type }\end{array}$ \\
\hline$M$ & 32 & $\mathrm{TBI}$ & 52.6 & 50.2 & -2.4 & 30.5 & 29.1 & -1.4 & short \\
\hline$F$ & 56 & $\mathrm{SAH}$ & 50.6 & 46.7 & -3.9 & 27.5 & 29.7 & 2.4 & short \\
\hline$M$ & 27 & TBI & 33.1 & 36 & 2.9 & 25.8 & 26.2 & 0.4 & small \\
\hline $\mathrm{M}$ & 61 & TBI & 31.5 & 33 & 1.5 & 26.1 & 24 & -2.1 & small \\
\hline$F$ & 60 & $\mathrm{ICH}$ & 34.9 & 40 & 5.1 & 28.3 & 28.4 & 0.1 & short \\
\hline$F$ & 38 & TBI & 45.2 & 48.0 & 2.8 & 29.5 & 28.5 & -1.0 & short \\
\hline$F$ & 72 & IS & 37.2 & 35.0 & -2.2 & 29.2 & 30.1 & 0.9 & short \\
\hline$M$ & 49 & TBI & 45.2 & 48.0 & 2.8 & 27.2 & 29.5 & 2.3 & short \\
\hline$F$ & 44 & $\mathrm{SAH}$ & 45.2 & 44.0 & -1.2 & 28.7 & 27.3 & -1.5 & short \\
\hline $\mathrm{M}$ & 51 & SAH & 45.6 & 43.9 & -1.7 & 29.0 & 28.0 & -1.0 & short \\
\hline$F$ & 68 & $\mathrm{ICH}$ & 41.4 & 44.0 & 2.6 & 27.3 & 28.1 & 0.8 & short \\
\hline$F$ & 39 & TBI & 56.7 & 55.2 & -1.5 & 37.5 & 35.2 & -2.3 & wide \\
\hline$M$ & 65 & $\mathrm{TBI}$ & 43.4 & 45.6 & 2.2 & 27.8 & 30.0 & 2.2 & short \\
\hline M & 75 & IS & 49.6 & 47.1 & -2.5 & 25.7 & 24.5 & -1.2 & small \\
\hline$M$ & 19 & TBI & 43.5 & 45 & 1.5 & 27.0 & 31.4 & 4.4 & typical \\
\hline F & 64 & $\mathrm{ICH}$ & 56.9 & 55.0 & -1.9 & 24.9 & 23.6 & -1.3 & narrow \\
\hline$M$ & 78 & $\mathrm{ICH}$ & 43.5 & 41.2 & -2.3 & 25.7 & 24 & -1.7 & small \\
\hline$F$ & 40 & SAH & 41.9 & 43.2 & 1.3 & 30.4 & 31.1 & 0.7 & short \\
\hline $\mathrm{M}$ & 23 & TBI & 43.5 & 40 & -3.5 & 22.0 & 25.0 & 3.0 & small \\
\hline$M$ & 67 & IS & 55.6 & 57.0 & 1.4 & 35.5 & 34.0 & -1.5 & wide \\
\hline$F$ & 76 & IS & 49.3 & 51.5 & 2.2 & 26.2 & 24.9 & -1.3 & small \\
\hline $\mathrm{F}$ & 39 & TBI & 52.1 & 50.2 & -1.9 & 30.0 & 31.2 & 1.2 & short \\
\hline $\mathrm{M}$ & 57 & $\mathrm{SAH}$ & 51.6 & 50.7 & -0.9 & 28.8 & 27.9 & -0.9 & short \\
\hline $\mathrm{M}$ & 65 & $\mathrm{ICH}$ & 57.2 & 56.0 & -1.2 & 25.3 & 26.0 & 0.7 & narrow \\
\hline$M$ & 41 & TBI & 56.0 & 57.8 & 1.8 & 29.9 & 31.5 & 1.6 & typical \\
\hline$F$ & 62 & TBI & 64.2 & 62.9 & -1.3 & 35.7 & 34.0 & -1.7 & large \\
\hline$M$ & 27 & TBI & 49.7 & 51.0 & 1.3 & 29.0 & 27.4 & -1.6 & short \\
\hline$F$ & 47 & SAH & 48.3 & 46.9 & -1.4 & 25.9 & 27.0 & 1.1 & small \\
\hline $\mathrm{F}$ & 56 & $\mathrm{ICH}$ & 60.1 & 57.4 & -2.6 & 28.6 & 30.0 & 1.4 & typical \\
\hline$M$ & 74 & IS & 56.2 & 58.0 & 1.8 & 26.0 & 24.8 & -1.2 & narrow \\
\hline$M$ & 18 & TBI & 50.5 & 52.0 & 1.5 & 29.1 & 30.8 & 0.9 & short \\
\hline$F$ & 51 & $\mathrm{ICH}$ & 65.2 & 63.6 & 1.4 & 27.9 & 29.0 & 1.1 & long \\
\hline$M$ & 67 & $\mathrm{ICH}$ & 63.8 & 62.2 & -1.6 & 34.7 & 33.0 & -1.7 & large \\
\hline $\mathrm{F}$ & 54 & $\mathrm{SAH}$ & 57.8 & 55.9 & -1.9 & 29.9 & 28.3 & -1.6 & typical \\
\hline
\end{tabular}

NL: notch length; MNW: maximum notch width; TBI: traumatic brain injury; SAH: subarachnoid hemorrhage; ICH: intracerebral hemorrhage; IS: ischemic stroke.

Rothon and Rai, ${ }^{3,13,14,15,16}$. Previous studies did not show any gender variation and, due to its anatomical structure, it is not expected to vary with different traumatic neurological injuries ${ }^{10}$. However, individual variation of this structure was clearly shown by Adler and Milhorat. Based on these findings, we can hypothesize that morphometric variations in the tentorial notch may be implicated in the different clinical presentations (relating to concussion and inertial injuries) and 

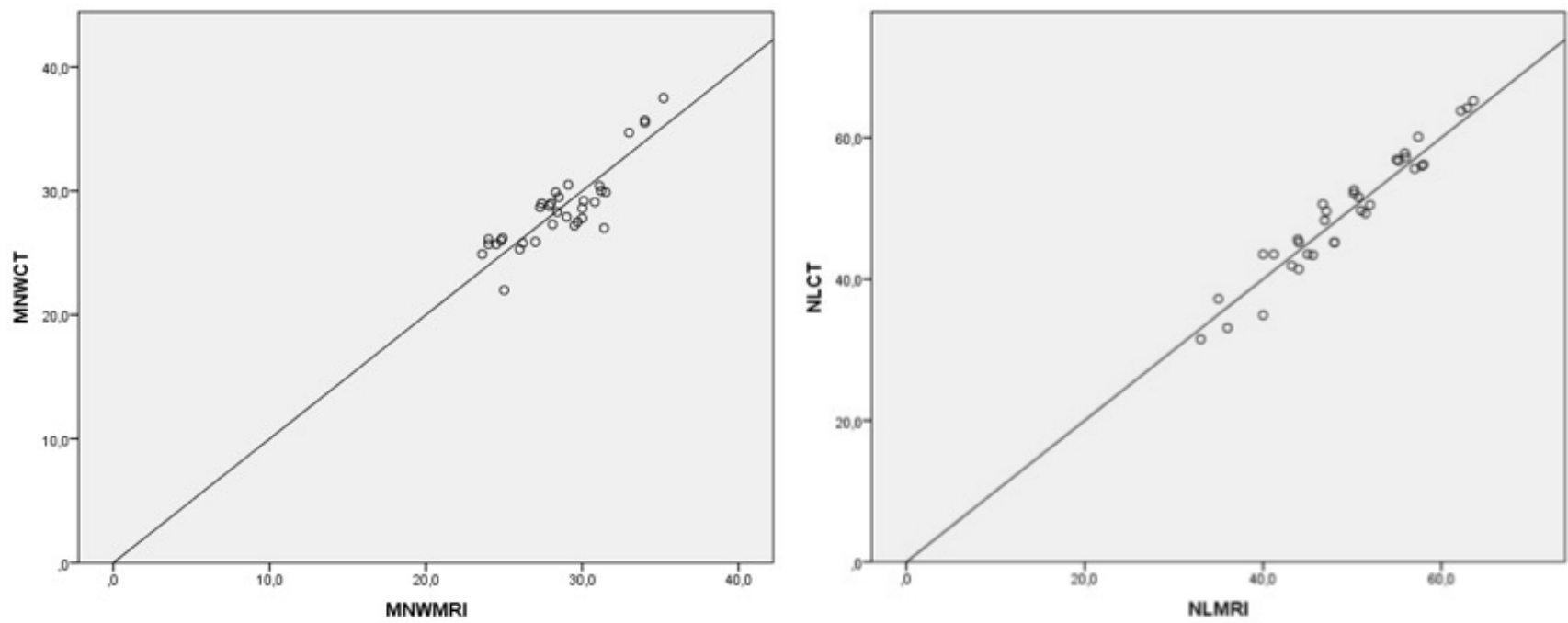

Left: plot of MNW measurements; Right: plot of NL measurements; NL: notch length; MNW: maximum notch width.

Figure 2. Correlation plots of tentorial notch measurements made via CT and MRI.
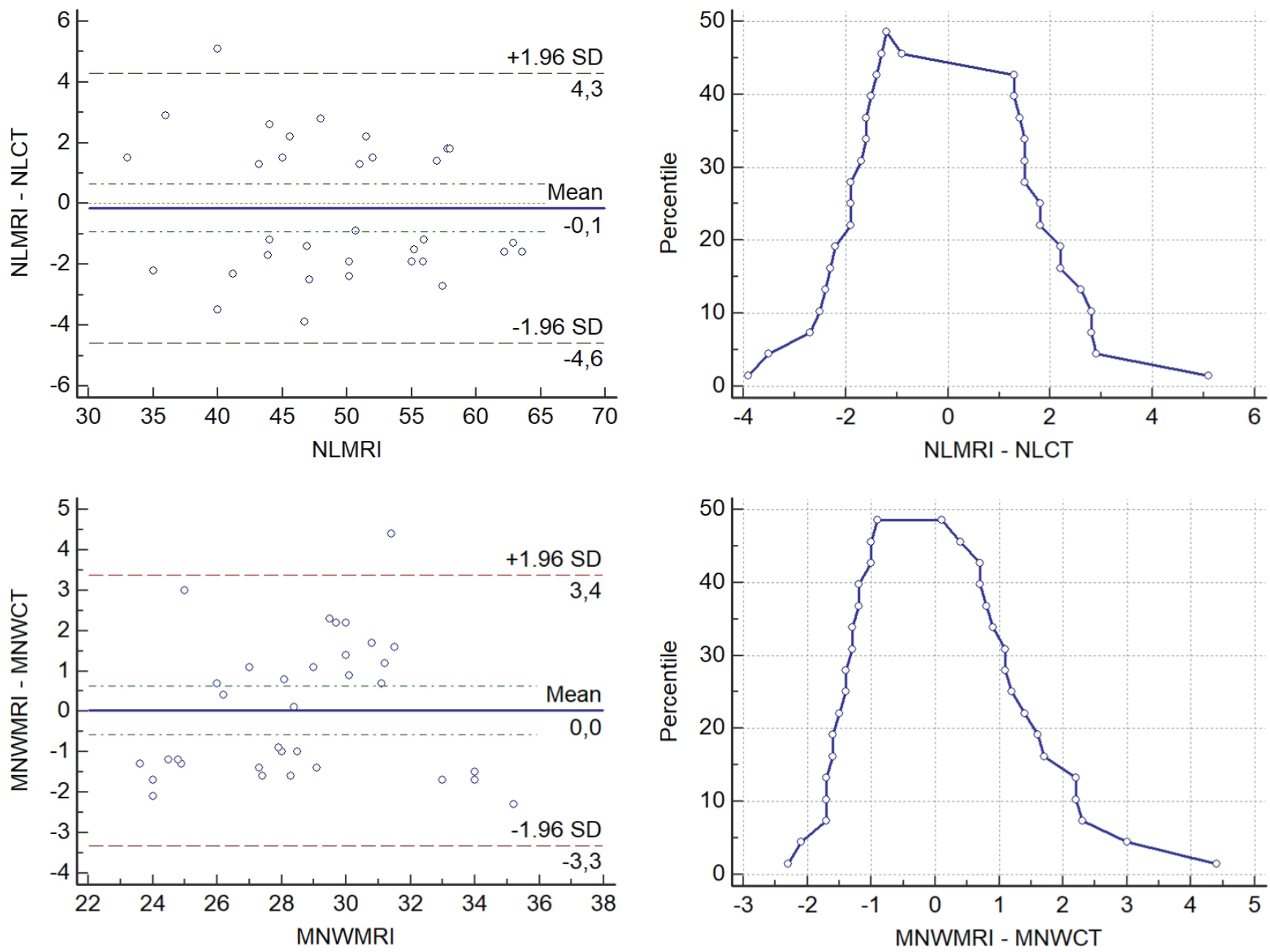

Upper left: Bland-Altman plot for NL measurements; Upper right: Mountain plot for NL measurements; Lower left: Bland-Altman plot for MNW measurements; Lower right: Mountain plot for MNW measurements; NL: notch length; MNW: maximum notch width.

Figure 3. Bland-Altman and mountain plots representing the agreement between the CT and MRI measurements of the tentorial notch. 

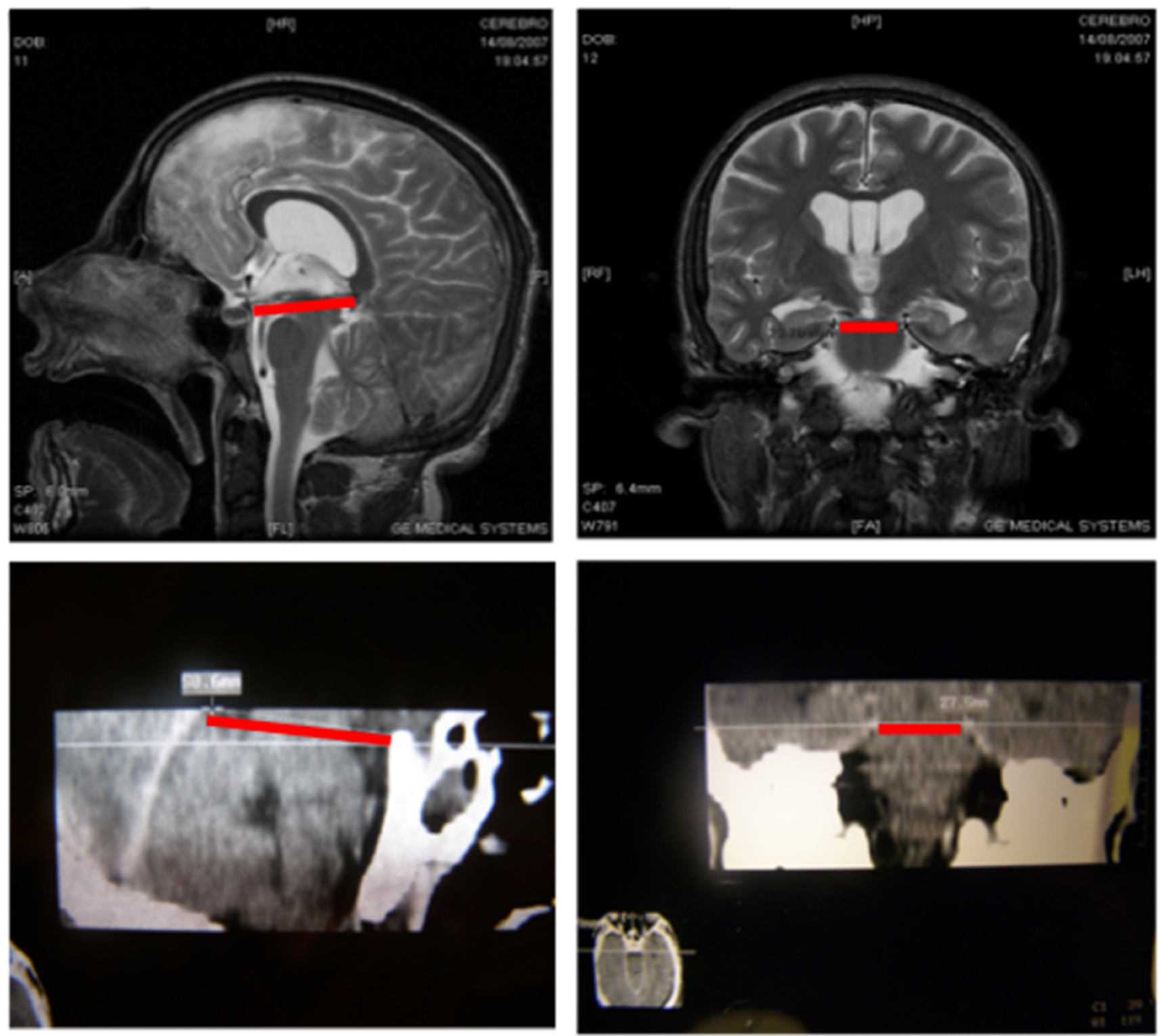

Upper left: MR sagittal image for NL measurement (NL: 46.7 mm); Upper right: MR coronal image for MNW measurement (MNW: 29.76 mm); Lower left: CT sagittal reconstruction image for NL measurement (NL: $50.6 \mathrm{~mm}$ ); Lower right: CT coronal reconstruction image for MNW measurement (MNW: $27.5 \mathrm{~mm}$ ). No patient data or name is visible on the images; NL: notch length; MNW: maximum notch width.

CT: computed tomography; MRI: magnetic resonance image

Figure 4. Example of CT and MRI evaluations from one patient.

Table 2. Tentorial notch subtypes. Comparison of our population measurements with those shown in the study by Adler and Milhorat. ${ }^{12}$ The subtypes defined in their study, with the respective measurements.

\begin{tabular}{|lcc}
\hline Type of notch & Frequency (\%) \\
\hline Wide & Adler et al. & Present study \\
\hline Narrow & $12(12 \%)$ & $2(6 \%)$ \\
Long & $15(15 \%)$ & $3(9 \%)$ \\
Short & $15(15 \%)$ & $1(3 \%)$ \\
Typical & $8(8 \%)$ & $15(44 \%)$ \\
Large & $24(24 \%)$ & $4(12 \%)$ \\
Small & $9(9 \%)$ & $2(6 \%)$ \\
\hline
\end{tabular}

Wide (MNW: $32-39$ mm, NL: midrange); Long (MNW: midrange, NL: 62-70 mm); Large (MNW: $32-39$ mm, NL: $62-70$ mm); Narrow (MNW: minor than 27.1, NL: midrange); Short (MNW: midrange, NL: minor than $53.5 \mathrm{~mm}$ ); Small (MNW: 24.5-27 mm); Typical (midrange, MNW: 27.1-31.9 mm, NL: 53.6-61.9 mm). 
clinical deterioration or neuroworsening (due to brainstem distortion and cerebral herniation as the maximum expression of intracranial mass effect) of different patients with the same anatomical lesions.

The present study showed that it is possible to recognize the necropsy findings that Adler and Milhorat described, through in vivo detection of the morphometric variability of the tentorial notch. To our knowledge, this is the first study to have measured the in vivo morphometric characteristics of the tentorial notch by means of CT in a sample of neurocritical patients. We focused our study on neurocritical patients due to the high risk of neuroworsening that is inherent to this type of patients and because of the need to find possible causes for this. In fact, different tentorium formats could exist and influence any patient with neurocritical disease who presents with a focal or diffuse mass lesion.

Good agreement was found between the measurements made via CT and those made via MRI. The latter is considered to be the gold standard for intracranial morphometry. In general, brain MRI is not used as often for investigating critical conditions as is $\mathrm{CT}$. Thus, our study provides validation for our CT protocol for measurement of the tentorial notch. This may make it possible to use $\mathrm{CT}$ as a practical tool for studying and categorizing the individual characteristics of the tentorial notch in neurocritical patients, as a further element to monitor in order to assess its involvement in neuroworsening ${ }^{17,18,19}$.

As put forward by Adler and Milhorat, we can also speculate that this purely structural and anatomical characteristic could constitute an individual factor to be considered in cases of acute neurodeterioration, which could also be detectable and recognizable clinically through a simple addition to the standard tomographic protocol ${ }^{12}$. Although it remains to be determined how clinically important such findings are, they could be a plausible explanation for what has frequently been observed clinically: dissimilar clinical evolution between different patients with focal mass lesions of equal volume and acuity. For example, the morphometry of the tentorium, together with the location and growth velocity of cerebral injuries, could play a role in determining different herniation patterns, such that certain anatomical features would confer "protection" whereas others would predispose to early brainstem lesion. In this regard, there is a notion that wide tentoria could provide a greater possibility of "accommodation" of the brain and could therefore tolerate greater midline shift without producing trans-tentorial brain herniation. However, this could just be the other way round, such that broad tentoria could facilitate early brain herniation.

Interestingly, in our study we found predominance of the "narrow", "short" and "small" types, which corresponded to tight tentoria, rather than "long", "wide" and "large" types, which corresponded to widely spread tentoria. We did not find any clear explanation of why tight tentoria predominated in our sample. These were probably chance findings due to the small sample size or, just possibly, due to differences between ethnicities.

Our study had limitations, particularly with regard to its small number of patients. Obviously, a larger sample and more comparative cases are needed in order to ratify or refute our findings. There is also a lack of proven association between the morphology of the tentorium and brain herniation or clinical outcome.

We can conclude that the anatomical variability of the tentorial notch was reliably detected in neurocritical patients by means of CT scans and MRI. Good agreement in the measurements made using these two imaging methods was found. Further studies will be needed in order to evaluate the clinical importance of this anatomical variability, especially with regard to the clinical evolution of focal mass lesions.

\section{REFERENCES}

1. Jefferson G. The tentorial pressure cone. Arch Neur Psych. 1938 Nov;40(5):857-76. https://doi.org/10.1001/ archneurpsyc.1938.02270110011001

2. Meyer A. Herniation of the brain. Arch Neur Psych. 1920 Oct;4(4):387400. https://doi.org/10.1001/archneurpsyc.1920.02180220036003

3. Reid WL. Cerebral herniation through the incisura tentorii. A clinical, pathological, and experimental study. Surgery. 1940 Nov 1;8(5):75670. https://doi.org/10.5555/uri:pii:S0039606040905190

4. Scheinker IM. Transtentorial herniation of the brain stem. A characteristic clinicopathologic syndrome; pathogenesis of hemorrhages in the brain stem. Arch Neur Psych. 1945 Apr;53(4):28998. https://doi.org/10.1001/archneurpsyc.1945.02300040035006

5. Schwarz GA, Rosner AA. Displacement and herniation of the hippocampal gyrus through the incisura tentorii. A clinicopathologic study. Arch Neur Psych. 1941 Aug;46(2):297-321. https://doi. org/10.1001/archneurpsyc.1941.02280200103005

6. Fisher CM. Brain herniation: a revision of classical concepts. Can J Neurol Sci. 1995 May;22(2):83-91. https://doi.org/10.1017/ S0317167100040142

7. Yamasaki F, Kodama Y, Hotta T, Yuki K, Taniguchi E, Hashizume A.
Magnetic resonance imaging of Kernohan's notch in chronic subdural hematoma. Brain Nerve. 1997 Jun 1;49(6):563-6.

8. Nguyen JP, Djindjian M, Brugières P, Badiane S, Melon E, Poirier J. Anatomy-computerized tomography correlations in transtentorial brain herniation. J Neuroradiol. 1989;16(3):181-96.

9. Reich JB, Sierra J, Camp W, Zanzonico P, Deck MD, Plum F. Magnetic resonance imaging measurements and clinical changes accompanying transtentorial and foramen magnum brain herniation. Ann Neurol. 1993 Feb;33(2):159-70. https://doi.org/10.1002/ ana.410330205

10. Corsellis JAN. Individual variation in the size of the tentorial opening. J Neurol Neurosurg Psychiatry. 1958 Nov;21(4):279-83. https://doi. org/10.1136/jnnp.21.4.279

11. Sunderland $S$. The tentorial notch and complications produced by herniations of the brain through that aperture. Br J Surg. 1958 Mar 18;45(193):422-38. https://doi.org/10.1002/bjs.18004519306

12. Adler DE, Milhorat TH. The tentorial notch: anatomical variation, morphometric analysis, and classification in 100 human autopsy cases. J Neurosurg. 2002 Jun;96(6):1103-12. https://doi.org/10.3171/ jns.2002.96.6.1103 
13. Kernohan JW, Woltman HW. Incisura of the crus due to contralateral brain tumor. Arch Neur Psych. 1929 Feb;21(2):274-87. https://doi. org/10.1001/archneurpsyc.1929.02210200030004

14. Klintworth GK. The comparative anatomy and phylogeny of the tentorium cerebelli. Anat Rec. 1968 Mar;160(3):635-42. https://doi. org/10.1002/ar.1091600312

15. Rhoton Jr AL. Tentorial incisura. Neurosurgery. 2000 Sep 1;47(3 Suppl 3):S131-53. https://doi.org/10.1097/00006123-200009001-00015

16. Osborn AG. The medial tentorium and incisura: normal and pathological anatomy. Neuroradiology. 1977 Apr 18;13(2):109-13. https://doi.org/10.1007/BF00339844
17. Rai R, Iwanaga J, Shokouhi G, Oskouian RJ, Tubbs RS. The Tentorium Cerebelli: a comprehensive review including its anatomy, embryology, and surgical techniques. Cureus. 2018 Jul 31;10(7):e3079. https://doi. org/10.7759/cureus.3079

18. Morris GF, Juuls N, Marshall SB, Benedict B, Marshall LF. Neurological deterioration as a potential alternative endpoint in human clinical trials of experimental pharmacological agents for treatment of severe traumatic brain injuries. Neurosurgery. 1998 Dec;43(6):1369-72.

19. Biestro A. Neurodeterioro (neuroworsening). In: Tobar AO, Plaza BC, editors. Evaluación y manejo avanzado en neurotrauma craneal. Chile: Universidad de Valparaíso-Editorial; 2004. p. 367-73. 